\title{
Racial Differences in the Diagnosis and Treatment of Prostate Cancer
}

\author{
Giuliano Di Pietro' ${ }^{1}$ Ganna Chornokur², Nagi B. Kumar², Chemar Davis², Jong Y. Park² \\ ${ }^{1}$ Department of Pharmacy, Federal University of Sergipe, Brazil \\ ${ }^{2}$ Department of Cancer Epidemiology, H. Lee Moffitt Cancer Center and Research Institute, Tampa, FL, USA
}

Disparities between African American and Caucasian men in prostate cancer (PCa) diagnosis and treatment in the United States have been well established, with significant racial disparities documented at all stages of PCa management, from differences in the type of treatment offered to progression-free survival or death. These disparities appear to be complex in nature, involving biological determinants as well as socioeconomic and cultural aspects. We present a review of the literature on racial disparities in the diagnosis of PCa, treatment, survival, and genetic susceptibility. Significant differences were found among African Americans and whites in the incidence and mortality rates; namely, African Americans are diagnosed with PCa at younger ages than whites and usually with more advanced stages of the disease, and also undergo prostate-specific antigen testing less frequently. However, the determinants of the high rate of incidence and aggressiveness of PCa in African Americans remain unresolved. This pattern can be attributed to socioeconomic status, detection occurring at advanced stages of the disease, biological aggressiveness, family history, and differences in genetic susceptibility. Another risk factor for PCa is obesity. We found many discrepancies regarding treatment, including a tendency for more African American patients to be in watchful waiting than whites. Many factors are responsible for the higher incidence and mortality rates in African Americans. Better screening, improved access to health insurance and clinics, and more homogeneous forms of treatment will contribute to the reduction of disparities between African Americans and white men in PCa incidence and mortality.

Keywords: Prostatic neoplasms; Healthcare disparities; African Americans

- Conflict of Interest: No potential conflict of interest relevant to this article was reported.

\section{INTRODUCTION}

Prostate cancer (PCa), the most common malignancy in adult men, is the second most common cancer and the fifth-highest cause of cancer mortality in the United States (US). The American Cancer Society estimates that 180,890 new cases and 26,120 deaths due to PCa will occur in 2016. The incidence rates between 2008 and 2012 were 131.5 and 21.4 deaths per 100,000 persons, respectively [1]. The recent decrease in the incidence of PCa was driven, in part, by the release of the US Preventive Services Task Force draft recommendation against prostatespecific antigen (PSA) screening in 2011 [2]. The incidence rates in different ethnic groups in the US are significantly different: 123.0 and 208.7 per 100,000 persons in non-Hispanic whites and African Americans, respectively. The mortality rates were 19.1 per 100,000 persons in non-Hispanic whites and 44.2 per 100,000 persons in African Americans [1]. Thus, African Americans suffer a disproportionate burden from PCa, having
Corresponding author: Jong Y Park (iD http://orcid.org/0000-0002-6384-6447 Department of Cancer Epidemiology, H. Lee Moffitt Cancer Center and Research Institute, Tampa, FL 33612, USA

E-mail: jong.park@moffitt.org / Tel: +1-813-745-1703 / Fax: +1-813-745-1720

Submitted: September 23, 2016 / Accepted after revision: October 14, 2016
This is an Open Access article distributed under the terms of the Creative Commons Attribution Non-Commercial License (http://creativecommons.org/licenses/by-nc/4.0/) which permits unrestricted non-commercial use, distribution, and reproduction in any medium, provided the original work is properly cited. 


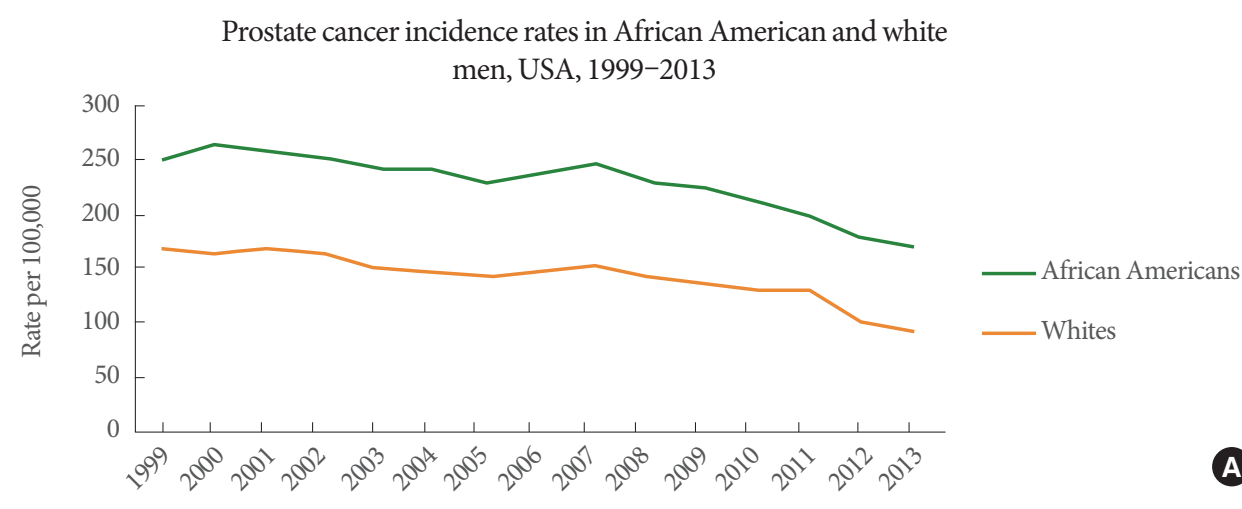

Prostate cancer disease-specific mortality rates in African American and white men, USA, 1999-2013

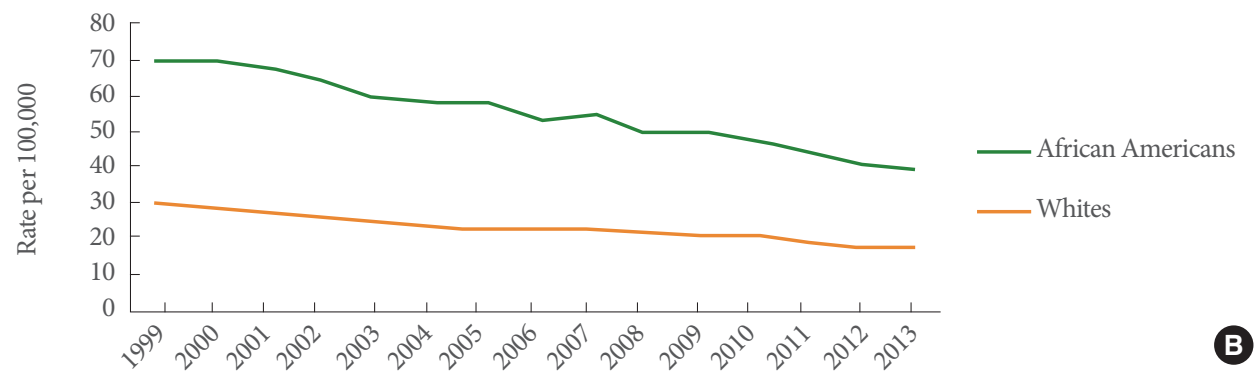

Fig. 1. Incidence rates (A) and disease-specific mortality rates (B) for prostate cancer in African American and white men between 1999 and 2013 [39].

the highest incidence and mortality rates of any racial or ethnic group (Fig. 1). The causes of these disparities are complicated and they may occur in part due to environmental factors, such as socioeconomic status, and biological differences, such as genetic susceptibility. Currently, the only well-established risk factors for PCa are age, race, and family history of the disease. Men who have a first-degree relative with a history of PCa are 2 to 3 times more likely to develop PCa [3].

The National Institutes of Health Surveillance Epidemiology and End Results (SEER) data between 1975 and 2012 showed that 309,289 men were diagnosed with PCa during this period, and that fatal PCa accounted for $17 \%$ of the cases. During the 10 -year period following diagnosis, PCa was the most common cause of death (34\%). In addition, African American men had an earlier mean age at diagnosis (69.1 years vs. 71.1 years) and shorter mean survival period (44.4 months vs. 48.4 months). The ratio of the mortality rates of $\mathrm{PCa}$ in African American and white men has not changed over the past few decades, with African American men showing a consistent 2.2-3.0 fold higher risk. In addition, this ratio was found to be 4.2 fold among young adults (45-49 years old) and 2.0 fold higher among older
African American men ( $>60$ years old) [4]. The lifetime probabilities of diagnosis or disease-specific death from PCa in US between 2010 and 2012 were 18.2\% and 4.4\% in African Americans, respectively, and $13.3 \%$ and $2.4 \%$ in non-Hispanic whites, respectively [3].

The Health and Retirement Study measured changes in PCa screening prevalence in US men aged over 50 years between 1996 and 2008, including 1,359 African Americans and 8,226 whites. The results showed an improvement from $62.0 \%$ to $71.2 \%$ in African Americans and from $68.6 \%$ to $71.3 \%$ in whites. These data indicated a significant time and race interaction and an increased prevalence of prostate screening in African American men [5].

In general, socioeconomic status is inversely correlated with incidence and mortality rates. African American men have lower levels of income, and only $15 \%$ of African American men have a bachelor's degree, in contrast to $30.7 \%$ of white men. A higher proportion of African American men than white men reported medical mistrust [6], which may explain why African American men receive screening tests less frequently. 


\section{DIAGNOSIS}

The disparities between African Americans and whites in PCa diagnosis have been well established in the US [7]. However, the contribution of PSA screening tests to the incidence rate is more controversial. The results of a US-based randomized trial indicated no reduction in PCa mortality as a result of PSA screening tests, while several European trials showed a modest benefit [3]. However, other important variables should be considered for early detection or screening.

The Selenium and Vitamin E Cancer Prevention Trial investigated whether supplementation with selenium, vitamin E, or both would reduce PCa incidence. This trial was performed between 2001 and 2004, and included 4,674 African Americans and 27,566 non-Hispanic white men ( $>55$ years old) with normal PSA levels $(<4.0 \mathrm{ng} / \mathrm{mL})$ and normal results of a digital rectal examination. Over 5.6 years of follow-up, 1,723 men were diagnosed with PCa. The researchers observed that African Americans were diagnosed younger (by a mean of 4.2 years), were less likely to have a college degree ( $33.2 \%$ vs. $55.4 \%$ completed college), and had a higher prevalence of diabetes, smoking, and obesity (38.9\% vs. $30.1 \%$ ) than white men. The incidence of PCa was significantly higher among African Americans in the trial [8]. Goovaerts et al. [8] observed that household median income and advanced-stage diagnosis were inversely correlated and that advanced-stage diagnosis was more common in African American (21\%-24\%) than in white men $(17 \%-18 \%)$ based on the Florida Cancer Data System $(n=$ 256,365).

In the SEER data, socioeconomic status was positively correlated with 5-year cause-specific survival in both racial groups. DeSantis et al. [3] similarly found that the risk of death from $\mathrm{PCa}$ in African Americans was consistently higher than in whites in all socioeconomic status strata. Among patients with the same high socioeconomic status, cancer screening was more common in whites than African Americans, and cancer detection was earlier in whites. Furthermore, nonaggressive tumors were found more often in whites than African Americans [9].

Trantham et al. [10] reported that nearly $25 \%$ of African Americans did not have a PSA test for at least 12 months in the first 5 years after initial PCa. Non-Hispanic white men were more likely to receive at least one annual test during the first 5 years after PCa treatment than men of other ethnic groups based on SEER data. African Americans men waited longer be- tween diagnosis and treatment than white men after adjusting for age, annual household income, level of education, and health insurance status [6]. In addition, among 62,644 high-risk and nonmetastatic cases (PSA $>20 \mathrm{ng} / \mathrm{mL}$, Gleason score of $8-10$, or stage $\geq$ cT3a) in the SEER data, the African American patients were more likely to exhibit elevated PSA levels (17.6\% vs. $9.9 \%, \mathrm{P}<0.001)[11]$.

Moses et al. [12] observed that African Americans had higher percentages of T1c disease and higher PSA levels than white men $(6.1 \mathrm{ng} / \mathrm{mL}$ vs. $4.7 \mathrm{ng} / \mathrm{mL}, \mathrm{P}<0.005)$ among surgically treated young PCa patients ( $<50$ years old) at Memorial SloanKettering Cancer Center. However, significant differences were not found in clinical or pathological characteristics between the 2 racial groups in the Gleason score, extracapsular extension, lymph node involvement, or seminal vesicle invasion. However, they found a significant difference in survival between African Americans and whites in locally confined cases, but not in patients with advanced disease. African American patients with locally advanced disease were at a greater risk of early biochemical recurrence than white patients.

\section{TREATMENT}

Based on to the current Clinical Practice Guidelines in Oncology of the National Comprehensive Cancer Network, the available options for PCa treatment are radical prostatectomy, external beam radiation therapy, brachytherapy, cryotherapy, androgen deprivation therapy, and combination therapy [13]. Many studies have been performed on disparities in health services and treatments offered to members of different ethnic and racial groups, especially in the US.

Powell et al. [14] performed survival analyses for both races in 2 distinct periods, the pre-PSA era (1973-1994) and the PSA era (1998-2005), using the SEER data [14]. They found that African American patients had a significantly lower survival rate than whites in both eras among patients who received surgical or radiation therapy. Furthermore, the proportion of African American patients with metastasis was significantly higher than the proportion of white patients with metastasis, and the mortality rate of African American patients was 2-3 times higher than that of white patients in both eras. Mahal et al. [15] reported that elderly African American patients ( $>70$ years of age) with high-risk localized PCa (PSA $>20 \mathrm{ng} / \mathrm{mL}$, Gleason score of $8-10$, or stage $\geq$ CT3a) received less definitive treatment, such as radical prostatectomy, radiation therapy, or combination 
therapy, than white men $(52.0 \%$ vs. $64.8 \%, \mathrm{P}<0.001)$. Among patients with high-risk localized PCa, African Americans had higher preoperative PSA levels (median, $8.0 \mathrm{ng} / \mathrm{mL}$ vs. $6.3 \mathrm{ng} /$ $\mathrm{mL} ; \mathrm{P}=0.001$ ), while white men were more likely to have T3T4 stage disease $(26.1 \%$ vs. $21.3 \%, \mathrm{P}=0.001)$. In both racial groups, insured patients were more likely to undergo definitive therapy than uninsured patients, although the difference was more pronounced in African American men. Therefore, medical insurance may reduce the health disparity between whites and African Americans regarding treatment [15].

Moses et al. [16], using the SEER database with 327,641 men diagnosed with clinically located PCa between 2004 and 2011, showed a significant difference in the treatment type received according to racial group. While $31.1 \%$ of African American men were treated with radical prostatectomy, $38.2 \%$ of white men received this form of treatment. It was also found that 26.8\% of African Americans received external beam radiation therapy, compared to $22.7 \%$ of white men. However, no significant difference in cryotherapy was found. This study also showed that the African Americans were more likely to experience treatment delays and postoperative complications and less likely to undergo lymph node dissection than white men. An independent study observed a similar treatment pattern. Data between 2007 and 2008 from the Diagnosis and Decisions in Prostate Cancer Treatment Outcomes trial showed that prostatectomy was the main treatment in $79.5 \%$ of whites and $69.4 \%$ of African Americans, and that African Americans were more likely to receive radiation therapy than white men $(22.6 \%$ vs. 16.1\%) [6].

In a study conducted at the Durham Veterans Affairs Medical Center, African American patients had a lower clinical stage than white patients $(\mathrm{P}=0.001)$, and were less likely to receive preradiation androgen deprivation therapy $(\mathrm{P}=0.013)$ [17]. Allott et al. [17] found a significant association between visceral fat area and aggressive PCa in African Americans $(\mathrm{P}=0.035)$, suggesting a potential association between obesity and the risk of aggressive PCa. However, this association was not found in white patients. This association between obesity and PCa was confirmed by us [18].

Wang et al. [19] reported that the treatments received between 2004 and 2011 varied significantly according to race. While a radical prostatectomy was performed in $39.8 \%$ of white men, this occurred in only $27.5 \%$ of African Americans. Moreover, this disparity persisted over time. Between 2004 and 2005, $27.7 \%$ of white patients underwent radical prostatectomy, in contrast to $19.9 \%$ of African American patients $(\mathrm{P}<0.001)$, and in the period between 2010 and 2011, this disparity was even greater $(44.6 \%$ vs. $34.1 \%, \mathrm{P}<0.001)$. Although patients had similar clinical characteristics, the treatment plan was different in different groups. A greater percentage of African Americans $(37.2 \%)$ received treatment with external beam radiation therapy, in contrast to $33.1 \%$ of white men $(\mathrm{P}<0.001)$. Androgen deprivation therapy was received by $9.5 \%$ of African Americans and $5.7 \%$ of white men $(\mathrm{P}<0.001)$. Additionally, $12.5 \%$ of African Americans were in watchful waiting, compared to only $7.2 \%$ of whites $(\mathrm{P}<0.001)[19]$.

\section{GENETIC SUSCEPTIBILITY}

As described above, African American men suffer from higher rates of aggressive PCa, including lethal cancers, than whites in the US [20]. However, the determinants of this high rate of incidence and aggressiveness of PCa in African Americans remain unresolved. This pattern may be attributed to socioeconomic status, detection at a late stage, biological aggressiveness [21], and differences in genetic susceptibility [18,22-28]. Selected characteristics and results of PCa genetic studies of African American populations are presented in Table 1.

Recently, a large analysis of the genetic contribution to PCa risk was performed at the Prostate Cancer Association Group to Investigate Cancer Associated Alterations in the Genome consortium, with DNA samples of over 40,000 Caucasians and 2,000 individuals of African descent from the US and Europe, identifying over 100 risk loci $[29,30]$. These genetic biomarkers were identified based upon analyses of a mostly Caucasian population. Few PCa genome-wide association studies have been performed on African American populations [31]. We and others have attempted to validate the risk loci identified in association studies or among whites [24,32-34]. However, as expected, most loci identified in whites were not confirmed in African-ancestry population association studies [18,22-27,3137]. However, some loci were confirmed, and some may explain the significant health disparities in PCa (Table 1). For example, we investigated the association between genetic variations and risk in both racial groups, and further explored whether these associations varied according to obesity. We found that two single-nucleotide polymorphisms (SNPs) in HNF1B were associated with PCa risk only in African American men. As expected, obesity was a significant risk factor in African American men but not whites. Interestingly, HNF1B 
Table 1. Characteristics and results of prostate cancer studies among African-ancestry populations

\begin{tabular}{|c|c|c|c|c|c|}
\hline Population (country) & Race & rs \# & Gene & OR 95\% (CI) & Reference \\
\hline \multirow[t]{2}{*}{ United States (US) } & B $136 / 123$ & rs7501939 & $H N F 1 B$ & $1.56(1.08-2.27)$ & 18 \\
\hline & W 147/142 & & & & \\
\hline \multirow[t]{2}{*}{ US } & B $124 / 116$ & & $A P E 1, X R C C 1$ & NS & 22 \\
\hline & W 228/219 & & & & \\
\hline \multirow[t]{2}{*}{ US } & B $127 / 120$ & & UGT2B17 del & NS & 23 \\
\hline & W 293/367 & & & & \\
\hline \multirow[t]{6}{*}{ US, United Kingdom } & B 4040/3748 & rs10486567 & $J A Z F 1$ & $1.18(1.08-1.29)$ & 24 \\
\hline & & rs10993994 & $M S M B$ & $1.12(1.03-1.21)$ & \\
\hline & & rs7931342 & $11 q 13$ & $1.15(1.03-1.29)$ & \\
\hline & & rs10896449 & - & $1.12(1.01-1.24)$ & \\
\hline & & rs5945572 & NUDT10/11 & $1.11(1.02-1.20)$ & \\
\hline & & rs5945619 & - & $1.09(1.00-1.18)$ & \\
\hline US, Ghana & B 5262/6554 & rs7210100 & $17 q 21$ & $1.51(1.35-1.69)$ & 25 \\
\hline \multirow[t]{2}{*}{ US, Africa, Caribbean } & B $1715 / 2363$ & - & GSTM1 & $0.90(0.83-0.97)$ & 26 \\
\hline & & & GSTT1 & $0.88(0.82-0.96)$ & \\
\hline \multirow[t]{3}{*}{ US } & В 4853/4678 & rs116041037 & PCAT1 & $2.45(1.65-3.62)$ & 27 \\
\hline & & rs6983561 & - & $1.47(1.21-1.79)$ & \\
\hline & & rs7210100 & ZNF652 & $1.51(1.35-1.69)$ & \\
\hline \multirow[t]{5}{*}{ US } & В $3425 / 3290$ & rs12202378 & $6 \mathrm{q} 22$ & $1.25(1.15-1.35)$ & 31 \\
\hline & & rs11228580 & $11 \mathrm{q} 13$ & $1.31(1.20-1.44)$ & \\
\hline & & rs6983561 & $8 \mathrm{q} 24$ & $1.29(1.19-1.39)$ & \\
\hline & & rs1456315 & - & $1.23(1.15-1.33)$ & \\
\hline & & rs6987409 & - & $1.42(1.28-1.57)$ & \\
\hline \multirow[t]{3}{*}{ US } & В $868 / 878$ & rs2660753 & $3 \mathrm{p} 12$ & $1.17(1.02-1.35)$ & 32 \\
\hline & & rs16901979 & $8 \mathrm{q} 24$ & $1.38(1.19-1.60)$ & \\
\hline & & rs13254738 & - & $1.36(1.17-1.58)$ & \\
\hline \multirow[t]{2}{*}{ US } & B $860 / 575$ & - & EHBP1, MSMB, HNF1B, NUDT10/11 & NS & 33 \\
\hline & W 468/419 & & & & \\
\hline \multirow[t]{4}{*}{ US } & B 454/301 & 10896449 & $11 \mathrm{q} 32$ & $0.70(0.54-0.93)$ & 34 \\
\hline & & 2735839 & $K L K 2$ & $0.78(0.60-1.00)$ & \\
\hline & & 443076 & TCF2 & $1.48(1.11-1.96)$ & \\
\hline & & 5945572 & NUDT11 & $1.48(1.01-2.16)$ & \\
\hline Ghana & B $474 / 458$ & 7918885 & GATA3 & $0.40(0.28-0.57)$ & 35 \\
\hline \multirow[t]{2}{*}{ US } & В 298 & - & $A R C A G$ repeat & $1.52(1.03-2.23)$ & 36 \\
\hline & W 413 & & & & \\
\hline \multirow[t]{2}{*}{ US } & B 56 & - & CYP3A4 & NS & 37 \\
\hline & W 54 & & & & \\
\hline
\end{tabular}

B, black; W, white; rs, reference single nucleotide polymorphism; OR, odds ratio; CI, confidence interval. 
rs7501939 was associated with PCa risk exclusively in obese African American men (odds ratio, 2.14; $\mathrm{P}=0.01$ ) [18].

Chang et al. [24] tested risk loci identified in white populations using 4,040 cases and 3,748 controls of African ancestry from 19 institutions in the US and United Kingdom under the Men of African Descent and Carcinoma of the Prostate consortium. Among 47 SNPs, including 21 from the 8q24 region, they validated 13, including 7 from the $8 \mathrm{q} 24$ region. Six SNPs were at JAZF1 (rs10486567), MSMB (rs10993994), 11q13 (rs12418451 and rs7931342), and NUDT10/11 (rs5945572 and rs5945619). The direction of association and odds ratios of the validated SNPs were similar to those observed in whites.

Recently we conducted a large genetic association study of an African American population with 9,531 subjects (4,853 cases and 4,678 controls) to validate previously identified risk loci for $\mathrm{PCa}$ and to assess their implications for the etiology of PCa. Among the 82 SNPs tested, 30 (37\%) were validated to have a significant association with PCa risk. We concluded that the presence of the same directionality of influence and similar effects in the African American population indicated that loci have the same biological functions across populations, although most risk loci were not confirmed [27]. Therefore, larger association studies of African American populations are needed to identify African American-specific risk loci for PCa.

\section{CONCLUSION}

Although this review has shown inequalities in the diagnosis and treatment of PCa among different racial, economic, and social groups, further research must be conducted to better understand the causes of these disparities. The therapeutic options recommended by the physician and the final decisions of patients undergoing definitive treatment should also be evaluated. Additionally, the quality of the healthcare environment, the resources available to patients and health service providers, as well as the knowledge and skills of the professionals involved play a role in these disparities.

Patients' understanding of the disease, acceptance of treatment, and possible complications may also differ substantially among different racial, cultural, and socioeconomic groups, leading patients to make different choices regarding treatment. A more even distribution of resources among health centers can help align the decisions made by providers about treatment, as well as the behavioral differences of patients regarding their decisions.
As discussed in this review, African Americans are more likely to be diagnosed with advanced stages of cancer when treatment options are more limited and often less effective. This may shape some of the disparities that we presented. Higher rates of comorbidities, such as obesity, diabetes and hypertension, among African American patients may also affect the treatment and survival rates in this population.

Improving the geographical distribution of federally qualified health centers that serve a large proportion of poor patients may be an effective mechanism for the prevention and control of PCa. These federally qualified health centers serve approximately 20 million patients annually in the US, and nearly twothirds of patients seen are ethnic minorities, low-income, and uninsured [38], indicating that these facilities have the potential to reduce health disparities in ethnic minorities and other underserved populations.

It is not known whether increased access to tertiary medical centers will provide an opportunity to reduce the disparities in the treatment of clinically aggressive PCa, especially considering the need for multimodal treatment and greater access to technologically advanced treatment. Although no evidence indicates that different responses to therapy to PCa contribute to racial disparities and patient survival, African Americans are underrepresented in clinical trials, making it difficult to assess the effectiveness of cancer therapies in African American patients.

Obesity has a significant positive association with PCa risk. For low-grade PCa, obesity was positively associated with risk among African American men, as presented in this review. This effect on low-grade cancer increased significantly with obesity in African Americans. For high-grade cancer, the risk associated with obesity is even higher among African Americans. Public policies that aim to reduce obesity among African Americans may be important in the prevention of PCa and other diseases in this population.

\section{REFERENCES}

1. 2016 Estimates [Internet]. Oklahoma City (OK): American Cancer Society, Cancer Statistics Center; c2016 [Internet]. Available from: https://cancerstatisticscenter.cancer.org/\#/.

2. Siegel R, Naishadham D, Jemal A. Cancer statistics, 2012. CA Cancer J Clin 2012;62:10-29.

3. DeSantis CE, Siegel RL, Sauer AG, Miller KD, Fedewa SA, Alcaraz KI, et al. Cancer statistics for African Americans, 2016: Progress 
and opportunities in reducing racial disparities. CA Cancer J Clin 2016;66:290-308.

4. Kelly SP, Rosenberg PS, Anderson WF, Andreotti G, Younes N, Cleary SD, et al. Trends in the incidence of fatal prostate cancer in the United States by race. Eur Urol 2016 Jul 27 [Epub]. https://doi. org/10.1016/j.eururo.2016.05.011.

5. Goins RT, Schure MB, Noonan C, Buchwald D. Prostate cancer screening among American Indians and Alaska natives: the health and retirement survey, 1996-2008. Prev Chronic Dis 2015;12:E123.

6. Kinlock BL, Thorpe RJ Jr, Howard DL, Bowie JV, Ross LE, Fakunle DO, et al. Racial disparity in time between first diagnosis and initial treatment of prostate cancer. Cancer Control 2016;23:47-51.

7. Chornokur G, Dalton K, Borysova ME, Kumar NB. Disparities at presentation, diagnosis, treatment, and survival in African American men, affected by prostate cancer. Prostate 2011;71:985-97.

8. Goovaerts P, Xiao H, Gwede CK, Tan F, Huang Y, Adunlin G, et al. Impact of age, race and socio-economic status on temporal trends in late-stage prostate cancer diagnosis in Florida. Spat Stat 2015; 14(Pt 100):321-37.

9. Kish JK, Yu M, Percy-Laurry A, Altekruse SF. Racial and ethnic disparities in cancer survival by neighborhood socioeconomic status in Surveillance, Epidemiology, and End Results (SEER) Registries. J Natl Cancer Inst Monogr 2014;2014:236-43.

10. Trantham LC, Nielsen ME, Mobley LR, Wheeler SB, Carpenter $\mathrm{WR}$, Biddle AK. Use of prostate-specific antigen testing as a disease surveillance tool following radical prostatectomy. Cancer 2013;119: 3523-30.

11. Mahal BA, Ziehr DR, Aizer AA, Hyatt AS, Lago-Hernandez C, Choueiri TK, et al. Racial disparities in an aging population: the relationship between age and race in the management of African American men with high-risk prostate cancer. J Geriatr Oncol 2014;5:3528.

12. Moses KA, Chen LY, Sjoberg DD, Bernstein M, Touijer KA. Black and White men younger than 50 years of age demonstrate similar outcomes after radical prostatectomy. BMC Urol 2014;14:98.

13. National Comprehensive Cancer Network clinical practice guidelines in oncology (NCCN Guidelines): Colon/rectal cancer [Internet]. Fort Wathington (PA): National Comprehensive Cancer Network; c2016 [cited 2016 Aug 19]. Available from: http://www.nccn. org/professionals/physician_gls/__guidelines.asp.

14. Powell IJ, Vigneau FD, Bock CH, Ruterbusch J, Heilbrun LK. Reducing prostate cancer racial disparity: evidence for aggressive early prostate cancer PSA testing of African American men. Cancer Epidemiol Biomarkers Prev 2014;23:1505-11.

15. Mahal BA, Ziehr DR, Aizer AA, Hyatt AS, Sammon JD, Schmid M, et al. Getting back to equal: the influence of insurance status on racial disparities in the treatment of African American men with high-risk prostate cancer. Urol Oncol 2014;32:1285-91.

16. Moses KA, Orom H, Brasel A, Gaddy J, Underwood W 3rd. Ra$\mathrm{cial} /$ ethnic differences in the relative risk of receipt of specific treatment among men with prostate cancer. Urol Oncol 2016;34:415.e7415.e12.

17. Allott EH, Howard LE, Song HJ, Sourbeer KN, Koontz BF, Salama $\mathrm{JK}$, et al. Racial differences in adipose tissue distribution and risk of aggressive prostate cancer among men undergoing radiotherapy. Cancer Epidemiol Biomarkers Prev 2014;23:2404-12.

18. Chornokur G, Amankwah EK, Davis SN, Phelan CM, Park JY, Pow-Sang J, et al. Variation in HNF1B and obesity may influence prostate cancer risk in African American men: a pilot study. Prostate Cancer 2013;2013:384594.

19. Wang EH, Yu JB, Abouassally R, Meropol NJ, Cooper G, Shah ND, et al. Disparities in treatment of patients with high-risk prostate cancer: results from a population-based cohort. Urology 2016;95: 88-94.

20. Rebbeck TR, Devesa SS, Chang BL, Bunker CH, Cheng I, Cooney $\mathrm{K}$, et al. Global patterns of prostate cancer incidence, aggressiveness, and mortality in men of african descent. Prostate Cancer 2013;2013:560857.

21. Underwood SM. Reducing the burden of cancer borne by African Americans: if not now, when? Cancer Epidemiol Biomarkers Prev 2003;12:270s-276s.

22. Chen L, Ambrosone CB, Lee J, Sellers TA, Pow-Sang J, Park JY. Association between polymorphisms in the DNA repair genes XRCC1 and APE1, and the risk of prostate cancer in white and black Americans. J Urol 2006;175:108-12.

23. Park J, Chen L, Ratnashinge L, Sellers TA, Tanner JP, Lee JH, et al. Deletion polymorphism of UDP-glucuronosyltransferase 2B17 and risk of prostate cancer in African American and Caucasian men. Cancer Epidemiol Biomarkers Prev 2006;15:1473-8.

24. Chang BL, Spangler E, Gallagher S, Haiman CA, Henderson B, Isaacs $\mathrm{W}$, et al. Validation of genome-wide prostate cancer associations in men of African descent. Cancer Epidemiol Biomarkers Prev 2011;20:23-32.

25. Haiman CA, Chen GK, Blot WJ, Strom SS, Berndt SI, Kittles RA, et al. Genome-wide association study of prostate cancer in men of African ancestry identifies a susceptibility locus at 17q21. Nat Genet 2011;43:570-3.

26. Taioli E, Flores-Obando RE, Agalliu I, Blanchet P, Bunker CH, Ferrell RE, et al. Multi-institutional prostate cancer study of genetic susceptibility in populations of African descent. Carcinogenesis 
2011;32:1361-5.

27. Han Y, Signorello LB, Strom SS, Kittles RA, Rybicki BA, Stanford $\mathrm{JL}$, et al. Generalizability of established prostate cancer risk variants in men of African ancestry. Int J Cancer 2015;136:1210-7.

28. Gusev A, Shi H, Kichaev G, Pomerantz M, Li F, Long HW, et al. Atlas of prostate cancer heritability in European and AfricanAmerican men pinpoints tissue-specific regulation. Nat Commun 2016;7:10979.

29. Eeles RA, Olama AA, Benlloch S, Saunders EJ, Leongamornlert DA, Tymrakiewicz M, et al. Identification of 23 new prostate cancer susceptibility loci using the iCOGS custom genotyping array. Nat Genet 2013;45:385-91, 391e1-2.

30. Amin Al Olama A, Dadaev T, Hazelett DJ, Li Q, Leongamornlert D, Saunders EJ, et al. Multiple novel prostate cancer susceptibility signals identified by fine-mapping of known risk loci among Europeans. Hum Mol Genet 2015;24:5589-602.

31. Haiman CA, Chen GK, Blot WJ, Strom SS, Berndt SI, Kittles RA, et al. Characterizing genetic risk at known prostate cancer susceptibility loci in African Americans. PLoS Genet 2011;7:e1001387.

32. Xu J, Kibel AS, Hu JJ, Turner AR, Pruett K, Zheng SL, et al. Prostate cancer risk associated loci in African Americans. Cancer Epidemiol Biomarkers Prev 2009;18:2145-9.

33. Waters KM, Le Marchand L, Kolonel LN, Monroe KR, Stram DO, Henderson BE, et al. Generalizability of associations from prostate cancer genome-wide association studies in multiple populations.
Cancer Epidemiol Biomarkers Prev 2009;18:1285-9.

34. Hooker S, Hernandez W, Chen H, Robbins C, Torres JB, Ahaghotu C, et al. Replication of prostate cancer risk loci on 8q24, 11q13, 17q12, 19q33, and Xp11 in African Americans. Prostate 2010;70: 270-5.

35. Cook MB, Wang Z, Yeboah ED, Tettey Y, Biritwum RB, Adjei AA, et al. A genome-wide association study of prostate cancer in West African men. Hum Genet 2014;133:509-21.

36. Powell IJ, Land SJ, Dey J, Heilbrun LK, Hughes MR, Sakr W, et al. The impact of CAG repeats in exon 1 of the androgen receptor on disease progression after prostatectomy. Cancer 2005;103:528-37.

37. Roach M 3rd, De Silvio M, Rebbick T, Grignon D, Rotman M, Wolkov $\mathrm{H}$, et al. Racial differences in CYP3A4 genotype and survival among men treated on Radiation Therapy Oncology Group (RTOG) 9202: a phase III randomized trial. Int J Radiat Oncol Biol Phys 2007;69:79-87.

38. Adams SA, Choi SK, Khang L, A Campbell D, Friedman DB, Eberth JM, et al. Decreased cancer mortality-to-incidence ratios with increased accessibility of federally qualified health centers. J Community Health 2015;40:633-41.

39. Prostate Cancer Rates by Race and Ethnicity [Internet]. Atlanta (GA): Centers for Disease Control and Prevention; [updated 2016 Jun 16; cited 2016 Aug 30]. Available from: http://www.cdc.gov/ cancer/prostate/statistics/race.htm. 